\title{
Lifestyle, dietary and treatment adherence pattern of uncontrolled diabetics in coastal Karnataka, India
}

Rashmi Kundapur ${ }^{1}$, Bhavesh Modi ${ }^{2}$, Lavannya T Mary³, Shreyaswi M Sathyanath ${ }^{4}$, Santhosh Poojary N ${ }^{5}$, Deepak Saxena ${ }^{6}$

${ }^{1}$ Professor Department of Community and Family Medicine, All India Institute of Medical Sciences Bibinagar, Hyderabad, ${ }^{2}$ Associate Professor, Department of Community Medicine, GMERS Gandhinagar Gujarat; ${ }^{3}$ PG, Department of Community Medicine, K.S. Hegde Medical Academy, Nitte Deemed to be University, Mangalore; ${ }^{4} \mathrm{MPH}$ scholar, University of Bradford, Bradford, United Kingdom; ${ }^{5}$ Medico-social worker, Department of Community Medicine, K.S. Hegde Medical Academy, Nitte Deemed to be University, Mangalore, ${ }^{6}$ Professor, Indian Institute of Public health Gandhinagar, Gujarat

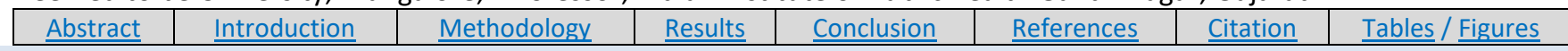

\section{Corresponding Author}

Dr Shreyaswi Sathyanath M, MPH scholar, University of Bradford, Bradford, United Kingdom

E Mail ID: siyasaidr@gmail.com

\section{Citation}

Kundapur R, Modi B, Mary LT, Sathyanath SM, Poojary SN, Saxena D. Lifestyle, dietary and treatment adherence pattern of uncontrolled diabetics in coastal Karnataka, India. Indian J Comm Health. 2021;33(3):446-450. https://doi.org/10.47203/IJCH.2021.v33i03.007

Source of Funding: Indian Institute of Public Health Gandhi Nagar Conflict of Interest: None declared

\section{Article Cycle}

Received: 04/06/2021; Revision: 13/08/2021; Accepted: 09/09/2021; Published: 30/09/2021

This work is licensed under a Creative Commons Attribution 4.0 International License.

\section{Abstract}

Background: Diabetes Mellitus shows a rising trend in India, driven by a combination of factors like sedentary lifestyle, unhealthy diet and tobacco use. The cornerstone for interventions to reduce this is lifestyle modification. Aim \& Objective: This study aims to determine lifestyle behaviours among uncontrolled diabetics in rural South India. Settings and Design: This is a pilot study conducted as part of a community trial which enrolled uncontrolled diabetics (Glycosylated haemoglobin, $\mathrm{HbA} 1 \mathrm{C}$ of $7 \%$ or more) selected from baseline survey of 2 RBS readings. Methods and Material: The sociodemographic details, lifestyle habits and treatment adherence of eligible participants were recorded with a validated questionnaire. Statistical analysis used: Data was compared among 2 groups of poor glycaemic control using Chi square test. Results: There was no significant association of age or gender with $\mathrm{HbA1C}$ levels. Majority were non-smokers, non-alcoholics and did not exercise. Higher proportions of those with hospital admissions, longer duration of disease and less frequent check-ups had poor control; but these were not statistically significant. Dietary control was inadequate. However, there were no significant association of dietary habits with poor control. Conclusions: Although overall adherence to medication and follow up was satisfactory, lifestyle modification is not being sufficiently followed.

\section{Keywords}

Lifestyle; Glycaemic Control; Rural; Diabetes; Surveys and Questionnaires; Tobacco Use

\section{Introduction}

Around 41 million people (71\% of deaths) die globally due to Noncommunicable diseases each year. 15 million deaths due to NCDs occur between 30-69 years, of which $85 \%$ premature deaths occur in the low- and middleincome countries, including India. The most common NCD deaths are due to cardiovascular diseases, followed by cancers, respiratory diseases and Diabetes Mellitus. (1 There are four shared risk factors that increase the risk which include tobacco use, physical inactivity, harmful use of alcohol and unhealthy diet. Therefore, one of the cornerstones for interventions to reduce the burden of NCDs is lifestyle modification. $(1,2)$

Lifestyle management encompasses several measures like diabetes self-management education (DSME) and selfmanagement support (DSMS). It is important for both the care providers and the patients to focus on assessment of lifestyle in the initial comprehensive evaluation. Each person with diabetes should engage actively in education, self-management and planning in nutrition including development of individualized eating plan. Similarly, body weight management is important especially for diabetics who are either overweight or obese. Smoking heightens the risk of CVDs in DM and smoking cessation is associated 
with amelioration of metabolic parameters along with reduction of blood pressure. $(3,4)$

\section{Aims \& Objectives}

1. To assess the lifestyle pattern including exercise and food habits of uncontrolled diabetics of village.

2. To determine the pattern of health check-up and adherence to medications among them

\section{Material \& Methods}

This is part of a larger study which was a community trial to reduce the burden of Non communicable diseases (hypertension and diabetes) in Karnataka. The intention was to introduce life style modification and physical activity intervention and compare it with control village.

As this was a baseline profile of a larger community intervention trial, the sample size was calculated depending on the hypothesis that planned lifestyle modification with regular drug intake can lead to a reduction of $\mathrm{Hb} 1 \mathrm{Ac}$ expected at $0.6 \%$ with standard deviation of around $0.1-0.2 \%$. Thus, the sample size was calculated to be 30 in each village. In this publication, we restrict ourselves to the baseline data among the uncontrolled diabetics to understand the interplay of the lifestyle and other factors among them. The eligible population of 2 villages enrolled with an average distance of $12 \mathrm{kms}$ in coastal Karnataka was included.

The enrolment was done for all the patients, irrespective of age, diagnosed with Type 2 Diabetes Mellitus who were on treatment but with $\mathrm{Hb} 1 \mathrm{Ac}$ more than $7 \%$, selected from a baseline survey of 2 RBS readings (average was considered). The exclusion criteria were participants with malignant hypertension, secondary hypertension, pregnancy or patients with severe disability, participants who are confused or comatose and unable to follow instructions. 67 study subjects who fit our selection criteria were selected by systematic random sampling using the family folders maintained in the subcentres.

The baseline perception, food habits, treatment adherence, hospital stay etc. of the eligible participants were recorded using a semi-structured and validated questionnaire after obtained informed consent as well as ethical clearance from the institutional ethics committee. Statistical analysis- Mean $\mathrm{HbA} 1 \mathrm{C}$ levels with standard deviation was recorded and paired t test was used for comparisons between groups. Frequency of food intake, and physical activity was compared for control of diabetes (HbA1C levels) using Chi square test.

\section{Results}

\section{Sociodemographic and health care details}

Out of the 67 subjects, $32(47.8 \%)$ had HbA1C between 79 whereas 35 (52.2\%) had 10 and above. Majority were between 41 to 60 yrs (55.2\%), females (71.6\%), performed no exercise $(88 \%)$, were non-smokers $(97 \%)$, did not consume alcohol (97\%), had hospital admissions in the past (92.5\%), had regular monthly check-ups (53.7\%), did not miss tablets $(76.2 \%)$, have had the disease since $<5 \mathrm{yrs}$ (61.2\%) and did not have any complications (82.1\%).

The high uncontrolled diabetics (Hb1Ac 10 and above) is seen particularly of age 41 to 60 years $(56.7 \%)$ and the higher proportion is also among females (56.2\%). However, there was no significant association of age or gender with $\mathrm{HbA} 1 \mathrm{C}$ levels. (Table 1)

Significantly higher proportion of those performed exercise (87.5\%) had high HbA1C of 10 or more, compared to those who did not exercise (47.5\%). But uncontrolled diabetes in general is associated with no exercise. (Table 2)

Higher proportions of those with history of hospital admissions had higher uncontrolled diabetes (54.8\%), but most had lesser than 2 days of admission. Similarly, higher proportion of those with $>5$ yrs disease $(68.5 \%)$ and with history of complications (58.4\%) were high uncontrolled diabetics with $\mathrm{HbA1C}$ of 10 or more; but none of these differences were seen to be statistically significant. The frequency of check-ups also differed wherein none of the patients with $\mathrm{HbA1C}>10 \%$ had monthly check-ups whereas comparatively higher proportion of those with lower HbA1c had check-ups on a monthly basis, but this was again not statistically significant. (Table 3 )

The food intake was haphazard and most with high sweet $(100 \%)$ or sugar intake $(55.6 \%)$ as extra intake (which is again excess carbohydrate intake) were seen to have higher glycaemic levels (HbA1C 10 and above). Hence, the higher uncontrolled diabetics ate both sugar and sweets excessively and never followed dietary restrictions. Salt restriction (79\% consuming less than 2 spoons) was the only aspect followed by the majority. Also, fructose eating was low (overall only $32.8 \%$ had fruit consumption of 1 or more). However, there were no significant difference in the proportion of any of the dietary habits between the 2 groups of poor glycaemic control. (Table 4)

\section{Discussion}

Overall, out of those with uncontrolled diabetes which involved our study population, more than half had high HbA1C (10 and above). This proportion of uncontrolled diabetes having very poor glycaemic control was higher compared to another study wherein only $4 \%$ had $\mathrm{HbA} 1 \mathrm{C}>$ $10 \%$ (5) and another study wherein only $24 \%$ subjects had a HbA1C above $8 \%$. (6) A study in Kerala however, found up to $45 \%$ of subjects with $\mathrm{HbA} 1 \mathrm{C}>9 \%$. (7)

In the current study, higher proportion of females had poorer glycaemic control (Hb1Ac 10 and above) compared to males. This is in contrast with the study done in Kerala wherein females showed better control of their diabetes than males. (7) However, in the current study, gender or age were not found significant determinants for poor glycaemic control similar to other studies done in elsewhere in India. $(8,9,10)$

The proportion of diabetics who performed exercise was low (12\%) in our study. This was similar to other studies 

among diabetics which found high proportion (56\%) of urban diabetics to be physically inactive. (11) However, community-based studies in general adult populations in rural areas have found the level of physical inactivity to be lower. $(12,13)$

Overall prevalence of smoking and alcohol was low in the population. Proportion of smoking and alcohol use was higher among the high uncontrolled diabetics with $\mathrm{HbA1C}$ levels more than 10 in our study though not statistically significant. Similarly, positive association between smoking and diabetes have been found in communitybased studies among diabetics. $(8,14)$

In our study, overall, $76 \%$ were compliant to medications and gave no history of missing tablets. This is similar to the compliance rate seen in another study among diabetics in rural Tamil Nadu and Bangalore. $(6,15)$ However, although our study did not find association between compliance to medications with glycaemic control, the study in rural Tamil Nadu found that increase in compliance rate has been associated with better glycaemic control. (6) In our study we found that higher proportions of those with longer duration of disease had very high uncontrolled diabetes (HbA1 C 10 or more) compared to those with $<5$ years disease or those who are newly diagnosed but this was not statistically significant. This could be due to the fact that in our study, we have compared the proportions between the subcategories of those diabetics who have high $\mathrm{HbA} 1 \mathrm{C}$ (7-9 and 10 or more) but not compared it with those who have achieved good glycaemic control. Similar to our study, longer diabetes duration has also been found to be associated with uncontrolled glycemia in other studies. $(5,6,8,10)$

With respect to diet, overall, only $33 \%$ had fruit consumption of 1 or more per week. Similar to this, other studies have found that only small proportion of diabetic subjects had satisfactory dietary practice including consumption of 5 fruit/ vegetable servings per week (8) and unsatisfactory diet including less frequent fruit consumption has been shown to be associated with poor glycaemic control in several studies. $(8,14)$ Up to $56 \%$ were consuming salt rich foods like pickle/ papad, but only $21 \%$ consuming more than 2 spoons of salt per day. High $\mathrm{Hb} \mathrm{A} 1 \mathrm{C}$ of 10 or more was found in those who ate both sugar and sweets. However, we did not find statistical association between salt restriction or excessive sweet consumption with poor glycaemic control. Following the recommended diet plan by taking a salt restricted diet and no consumption or occasional consumption of sweets has been seen to be associated with better glycaemic control in other studies as well. $(14,15,16)$

\section{Conclusion}

Out of the uncontrolled diabetics, the high proportion of those with $\mathrm{HbA1C}$ of 10 or more is worrisome, and in addition majority of them are not following lifestyle modifications including exercise or healthy eating plan. However, it is those components of health eating which were not practiced which needs to be specifically addressed; like decreasing the consumption of sweets or added sugars and increasing the consumption of fruits. Furthermore, the low proportion of the rural diabetics who are either smoking or consuming alcohol is encouraging. With respect to components of treatment and follow up, better practices are seen with majority of the subjects being adherent to medications and coming for monthly check-ups.

\section{Recommendation}

Based on the current study we recommend that lifestyle interventions among uncontrolled diabetics in rural areas should focus on dietary modifications more than other components. Also, we recommend further studies, probably population based interventional trials in larger sample to explore the type and mode of intervention in the form of dietary advice tailored to the rural diabetic population.

\section{Limitation of the study}

One of the limitations of the study is that the generalizability of the findings has to be interpreted cautiously keeping in mind that, this is a baseline polit study among only the uncontrolled diabetics and we have not compared with the general population or with those diabetics who have achieved good glycaemic control.

\section{Relevance of the study}

Rural diabetics have different patterns of lifestyle compared to their urban counterparts. Low levels of smoking and alcohol is seen; hence the focus needs to be on addressing the unhealthy patterns of diet among them. This study sheds light on this, to increase focus on particular aspect of lifestyle management.

\section{Authors Contribution}

All authors have contributed equally.

\section{References}

1. Non communicable diseases [Internet]. [Accessed on 08/10/20]. Available from: https://www.who.int/news-room/factsheets/detail/noncommunicable-diseases

2. Tandon N, Anjana RM, Mohan V, Kaur T, Afshin A, Ong K, et al. The increasing burden of diabetes and variations among the states of India: The Global Burden of Disease Study 1990-2016. The Lancet Global Health. 2018;6(12): e1352-62.

3. WHO | Do lifestyle interventions work in developing countries? Findings from the Isfahan Healthy Heart Program in the Islamic Republic of Iran [Internet]. World Health Organization; [Accessed on 25/09/20]. Available from: https://www.who.int/bulletin/volumes/87/1/07-049841/en/

4. Lifestyle Management: Standards of Medical Care in Diabetes- The American Diabetes Association. Diabetes Care. 2019;42(Supplement 1): S46-60.

5. Borgharkar SS, Das SS. Real-world evidence of glycaemic control among patients with type 2 diabetes mellitus in India: the TIGHT study. BMJ Open Diabetes Res Care. 2019;7(1): e000654.

6. Muliyil DE, Vellaiputhiyavan K, Alex R, Mohan VR. Compliance to treatment among type 2 diabetics receiving care at peripheral 
INDIAN JOURNAL OF COMMUNITY HEALTH / VOL 33 / ISSUE NO 03 / JUL-SEP 2021 mobile clinics in a rural block of Vellore District, Southern India. J Family Med Prim Care. 2017;6(2):330-5.

7. Kumar SP, Sandhya A. A study on the glycaemic, lipid and blood pressure control among the type 2 diabetes patients of north Kerala, India. Indian Heart Journal. 2018;70(4):482-5.

8. Pan T, Dasgupta A, Suman S, Paul B, Banerjee R, Burman J. Assessment of glycaemic control in patients with type 2 diabetes: a clinic-based study in a slum of Kolkata. International Journal of Community Medicine and Public Health. 2018;5(11):4768-72.

9. Rathi A, Saha K, Ramalingam A. Correlates of poor glycaemic control among diabetic patients who attended 2 diabetic clinics in Delhi. J Bio Innov. 2017;6(2):165-75.

10. Goyal J, Kumar N, Sharma M, Raghav S, Bhatia PS. Factors Affecting Glycaemic Control among Patients with Type 2 Diabetes at a Tertiary Health Care Centre of Western UP region: A CrossSectional Study. Int J Health Sci Res. 2019;9(3):12-20.

11. Paulin G, Subramanian R. Physical Inactivity among Diabetic Patients in Urban Tamil Nadu: A Community-Based Study. J Community Med Health Educ 2019;9(2):1-5. Check
[Lifestyle, dietary and treatment...] | Kundapur R et al

12. Newtonraj A, Vincent A, Gowtham P, Haritha S, Ilaveyini S. Level of insufficient physical activity among adults in a rural area of South India: A population-based cross-sectional study. J Curr Res Sci Med. 2019;5(2):105-9.

13. Devamani CS, Oommen AM, Mini G, Abraham VJ, George K. Levels of Physical Inactivity in Rural and Urban Tamil Nadu, India: A Cross-Sectional Study. Journal of Clinical and Preventive Cardiology 2019;8(1):13-7.

14. Sekhar CC, Babu DS, Krishna GA, Deepthi CS, Kalluri JB. A Study on Assessment of Level of Self-Care Practices among Known Type 2 Diabetes Patients in Rural Field Practice Area of South India. International Journal of Medicine and Public Health 2020; 10 (1):5.

15. De P, Banu S, Muthukumar D. Predictors of poor glycaemic control in type 2 diabetic patients in South Indian population. International Journal of Research in Medical Sciences. 2018;6(2):545-50.

16. Suguna A, Magal AS, Stany A, Sulekha T, Prethesh K. Suguna A, Magal AS, Stany A, Sulekha T, Prethesh K. Evaluation of self-care practices among diabetic patients in a rural area of Bangalore district, India. Int J Curr Res Aca Rev 2015; 3(6):415-22

\section{Tables}

\section{TABLE 1 AGE \& GENDER DISTRIBUTION OF DIABETICS BASED ON HB1AC AT BASELINE (ORIGINAL)}

\begin{tabular}{|l|l|l|l|l|l|l|}
\hline $\begin{array}{l}\text { HbA1C } \\
\text { Age Group }\end{array}$ & $7-9$ & $\%$ & 10 and above & \multicolumn{2}{c|}{ p value } \\
\hline $\begin{array}{l}\text { Up to 40 } \\
\text { 41-60 }\end{array}$ & 3 & 42.8 & 4 & 57.2 & $7(10.5 \%)$ & 0.782 \\
\hline $\mathbf{6 1 - 8 0}$ & 16 & 43.2 & 21 & 56.7 & $37(55.2 \%)$ & \\
\hline Gender & 13 & 56.5 & 10 & 43.5 & $23(34.3 \%)$ & 0.296 \\
\hline Male & 11 & 57.9 & 8 & 42.1 & $19(28.4 \%)$ & \\
\hline Female & 21 & 43.8 & 27 & 56.2 & $48(71.6 \%)$ & \\
\hline
\end{tabular}

\section{TABLE 2 LIFESTYLE PATTERN OF DIABETICS BASED ON HB1AC (ORIGINAL)}

\begin{tabular}{|c|c|c|c|c|c|c|}
\hline HbA1C & $7-9$ & $\%$ & 10 and above & $\%$ & Total & P value \\
\hline \multicolumn{7}{|l|}{ Exercise } \\
\hline Yes & 1 & 12.5 & 7 & 87.5 & $8(11.9 \%)$ & \multirow[t]{2}{*}{0.033} \\
\hline No & 31 & 52.5 & 28 & 47.5 & $59(88.1 \%)$ & \\
\hline \multicolumn{7}{|c|}{ Hours/week } \\
\hline Up to 3 & 1 & 25 & 4 & 75 & $5(62.5 \%)$ & \multirow[t]{2}{*}{0.407} \\
\hline$>3$ & 0 & 0 & 3 & 100 & $3(37.5 \%)$ & \\
\hline \multicolumn{7}{|l|}{ Smoking } \\
\hline Yes & 0 & 0 & 2 & 100 & $2(3 \%)$ & \multirow[t]{2}{*}{0.169} \\
\hline No & 32 & 49.2 & 33 & 50.8 & $65(97 \%)$ & \\
\hline \multicolumn{7}{|c|}{ Cigarettes/day } \\
\hline Up to 2 & 0 & 0 & 2 & 100 & 2 & \multirow[t]{2}{*}{1} \\
\hline 3 or more & 0 & 0 & 0 & 0 & 0 & \\
\hline \multicolumn{7}{|l|}{ Alcohol } \\
\hline Yes & 0 & 0 & 2 & 100 & $2(3 \%)$ & \multirow[t]{2}{*}{0.163} \\
\hline No & 32 & 49.2 & 33 & 50.8 & $65(97 \%)$ & \\
\hline \multicolumn{7}{|c|}{ Alcohol ml/week } \\
\hline Up to 60 & 0 & 0 & 2 & 100 & 2 & \multirow[t]{2}{*}{1} \\
\hline$>60$ & 0 & 0 & 0 & 0 & 0 & \\
\hline
\end{tabular}

\section{TABLE 3 HEALTH CHECKUP \& TREATMENT ADHERENCE OF DIABETICS BASED ON HB1AC (ORIGINAL)}

\begin{tabular}{|c|c|c|c|c|c|c|}
\hline $\mathrm{Hb} 1 \mathrm{Ac}$ & $7-9$ & $\%$ & 10 and above & $\%$ & Total & P value \\
\hline \multicolumn{7}{|c|}{ Frequency of checkup } \\
\hline Monthly & 22 & 61.1 & 14 & 38.9 & $36(53.7 \%)$ & \multirow[t]{3}{*}{0.112} \\
\hline Once in 6 months & 10 & 52.6 & 9 & 46.4 & $19(28.4 \%)$ & \\
\hline Yearly & 0 & 0 & 12 & 100 & $12(17.9 \%)$ & \\
\hline \multicolumn{7}{|l|}{ Hospital admission } \\
\hline Yes & 28 & 45.2 & 34 & 54.8 & $62(92.5 \%)$ & \multirow[t]{2}{*}{0.133} \\
\hline No & 4 & 80 & 1 & 20 & $5(7.5 \%)$ & \\
\hline
\end{tabular}


INDIAN JOURNAL OF COMMUNITY HEALTH / VOL 33 / ISSUE NO 03 / JUL-SEP 2021

\begin{tabular}{|c|c|c|c|c|c|c|}
\hline$<2$ & 26 & 50 & 26 & 50 & 52 (84\%) & \multirow{2}{*}{0.08} \\
\hline 2 or more & 2 & 20 & 8 & 80 & $10(16 \%)$ & \\
\hline \multicolumn{7}{|c|}{ Missing tablets } \\
\hline Yes & 8 & 50 & 8 & 50 & $16(23.8 \%)$ & \multirow[t]{2}{*}{0.837} \\
\hline No & 24 & 47.1 & 27 & 52.9 & $51(76.2 \%)$ & \\
\hline \multicolumn{7}{|c|}{ Years since DM } \\
\hline 1st time & 5 & 71.4 & 2 & 28.6 & 7 (10.5\%) & \multirow[t]{3}{*}{0.152} \\
\hline$<5 y$ & 21 & 52.5 & 20 & 47.5 & $41(61.2 \%)$ & \\
\hline$>5 y$ & 6 & 31.5 & 13 & 68.5 & $19(28.3 \%)$ & \\
\hline \multicolumn{7}{|c|}{ Complications } \\
\hline Yes & 5 & 41.6 & 7 & 58.4 & $12(17.9 \%)$ & \multirow[t]{2}{*}{0.64} \\
\hline No & 27 & 49 & 28 & 51 & $55(82.1 \%)$ & \\
\hline
\end{tabular}

TABLE 4 DIETARY PATTERN OF DIABETICS BASED ON HB1AC (ORIGINAL)

\begin{tabular}{|c|c|c|c|c|c|c|}
\hline \multirow[t]{2}{*}{ HbA1c } & $7-9$ & $\%$ & 10 and above & $\%$ & Total & P value \\
\hline & \multicolumn{6}{|c|}{ Servings per week } \\
\hline \multicolumn{7}{|l|}{ Pickles/ papad } \\
\hline Yes & 7 & 43.75 & 9 & 56.25 & $16(23.9 \%)$ & \multirow[t]{2}{*}{0.712} \\
\hline \multirow[t]{2}{*}{ No } & 25 & 49.01 & 26 & 50.99 & $51(76.1 \%)$ & \\
\hline & \multicolumn{6}{|c|}{ Cooked grains/day } \\
\hline Up to 5 bowls & 19 & 55.88 & 15 & 44.22 & $34(50.7 \%)$ & 0.176 \\
\hline \multirow[t]{2}{*}{$>5$ bowls } & 13 & 39.39 & 20 & 60.61 & $33(49.3 \%)$ & \\
\hline & \multicolumn{6}{|c|}{ Vegetables/day } \\
\hline Up to 2 bowls & 17 & 48.57 & 18 & 51.43 & $35(52.2 \%)$ & \multirow[t]{2}{*}{0.89} \\
\hline \multirow[t]{2}{*}{$>2$ bowls } & 15 & 46.88 & 17 & 53.22 & $32(47.8 \%)$ & \\
\hline & \multicolumn{6}{|c|}{ Fruits } \\
\hline$<1$ & 18 & 40 & 27 & 60 & $45(67.2 \%)$ & \multirow[t]{2}{*}{0.068} \\
\hline \multirow[t]{2}{*}{1 or more } & 14 & 63.63 & 8 & 36.37 & $22(32.8 \%)$ & \\
\hline & \multicolumn{6}{|c|}{ Milk/day } \\
\hline Up to $500 \mathrm{~mL}$ & 32 & 49.23 & 33 & 50.77 & 65 (97\%) & 0.169 \\
\hline \multirow[t]{2}{*}{$>500 \mathrm{~mL}$} & 0 & 0 & 2 & 100 & $2(3 \%)$ & \\
\hline & \multicolumn{6}{|c|}{ Nuts/legumes per week } \\
\hline Up to 2 bowls & 25 & 51 & 24 & 49 & 49 (73.1\%) & \multirow[t]{2}{*}{0.378} \\
\hline \multirow[t]{2}{*}{$>2$ bowls } & 7 & 38.9 & 11 & 61.1 & $18(26.9 \%)$ & \\
\hline & \multicolumn{6}{|c|}{ Sweets/day } \\
\hline Up to 1 & 32 & 49.2 & 33 & 50.8 & $65(97 \%)$ & \multirow[t]{2}{*}{0.169} \\
\hline \multirow[t]{2}{*}{$>1$} & 0 & 0 & 2 & 100 & $2(3 \%)$ & \\
\hline & \multicolumn{6}{|c|}{ Oil spoons/day } \\
\hline Up to 2 & 27 & 54 & 23 & 46 & $50(74.6 \%)$ & \multirow[t]{2}{*}{0.079} \\
\hline \multirow[t]{2}{*}{$>2$} & 5 & 29.4 & 12 & 70.6 & $17(25.4 \%)$ & \\
\hline & \multicolumn{6}{|c|}{ Sugar spoons/day } \\
\hline Up to 2 & 28 & 48.2 & 30 & 51.8 & $58(86.6 \%)$ & \multirow[t]{2}{*}{0.83} \\
\hline \multirow[t]{2}{*}{$>2$} & 4 & 44.4 & 5 & 55.6 & $9(13.4 \%)$ & \\
\hline & \multicolumn{6}{|c|}{ Salt spoons } \\
\hline Up to 2 & 27 & 50.9 & 26 & 49.1 & $53(79.1 \%)$ & 0.31 \\
\hline$>2$ & 5 & 35.7 & 9 & 64.3 & $14(20.9 \%)$ & \\
\hline & Me & eek & & & & \\
\hline Not taking & 0 & 0 & 0 & 0 & 0 & 0.99 \\
\hline Up to 5 bowls & 17 & 48.5 & 18 & 51.5 & $35(52.2 \%)$ & \\
\hline$>5$ bowls & 15 & 46.8 & 17 & 53.2 & $32(47.8 \%)$ & \\
\hline
\end{tabular}

